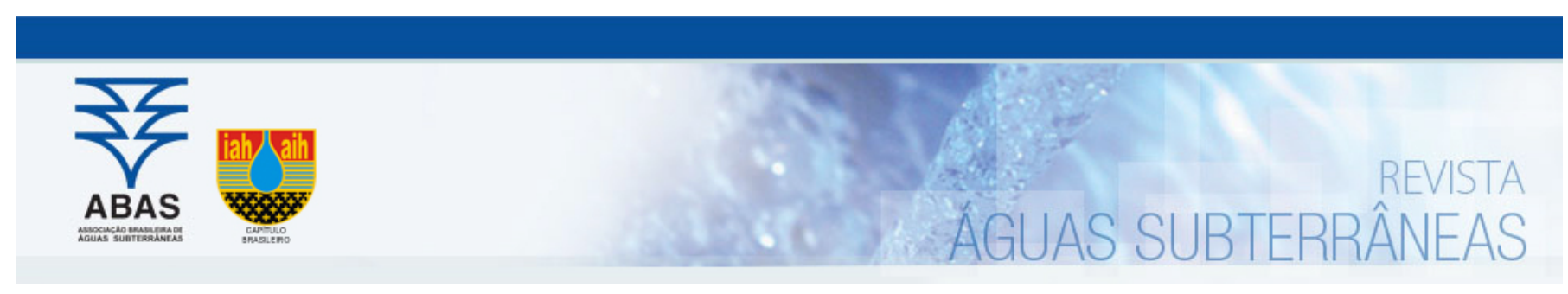

Artigos

\title{
Evolução da contribuição do Sistema Aquífero Urucuia para o Rio São Francisco, Brasil
}

\section{Evolution of Urucuia Aquifer System contribution to São Francisco river, Brazil}

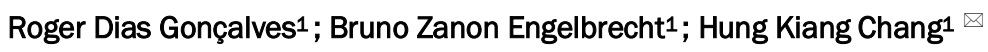 \\ ${ }^{1}$ Laboratório de Estudos de Bacias da Universidade Estadual Paulista "Júlio de Mesquita Filho" (LEBAC/UNESP), Rio Claro, SP, Brasil.
}

$\bowtie$ rdgon@hotmail.com, brunoz@rc.unesp.br, chang@rc.unesp.br

Resumo

Palavras-chave:

Fluxo de base.

Separação de hidrogramas.

Gestão de Recursos Hídricos.

o Sistema Aquífero Urucuia (SAU) é o mais importante da bacia hidrográfica do Rio São Francisco; possui produtividade elevada, mantém uma vasta área de irrigação e representa aproximadamente $41 \%$ da disponibilidade hídrica subterrânea de toda a bacia. Seu escoamento de base é o principal responsável por manter as vazões do Rio São Francisco nas estações secas, de maneira que o conhecimento da variação dessa contribuição ao longo do tempo é de suma importância. 0 objetivo deste trabalho é analisar o comportamento temporal e estimar a contribuição do SAU em todas as sub-bacias tributárias do Rio São Francisco. Foram utilizadas informações de 45 estações fluviométricas distribuídas em todo o SAU, analisadas pelo método de mínimos locais para separação de escoamentos superficial e subterrâneo em hidrogramas. A média do fluxo de base é de aproximadamente $200 \mathrm{~mm} / \mathrm{ano}\left(570 \mathrm{~m}^{3} / \mathrm{s}\right)$. Dentre os ciclos presentes no último século, o mais marcante e presente em toda a extensão do aquífero teve seu pico em 1980, com 280 mm/ano $\left(792 \mathrm{~m}^{3} / \mathrm{s}\right)$ de contribuição para o Rio São Francisco; desde então apresenta padrão de queda contínua, totalizando uma diminuição de $49 \%$ (390 m³ $/ \mathrm{s}$ ). Independente dos efeitos causadores desta queda, naturais e/ou antrópicos, é preponderante a tomada de medidas para garantir a sustentabilidade destes recursos, visto que a diminuição sistemática de água potável acarreta em grandes estresses socioeconômicos.

Abstract

Keywords:

Baseflow.

Hydrographs separation.

Water Resources Management.

Revisado por pares.

Recebido em: 18/08/2017.

Aprovado em: 04/12/2017.

\begin{abstract}
The Urucuia Aquifer System (UAS) is the most important aquifer located in the São Francisco river watershed, with high productivity, maintains large irrigated areas and represents about $41 \%$ of the basin's groundwater resources. Its baseflow is responsible for the maintenance of São Francisco low flow regimes, for this reason it's important to have a correct understanding about the baseflow variations in time. This work aims to analyze the variation of the Urucuia contribution in all São Francisco catchments using local minimum method of hydrographs separation in 45 gauge stations. The baseflow average is about $200 \mathrm{~mm} / \mathrm{year}$ ( 570 $\left.\mathrm{m}^{3} / \mathrm{s}\right)$. Among the last century cycles, the most notable and extensive one had its peak in 1980 with $280 \mathrm{~mm} /$ year $(792 \mathrm{~m} / \mathrm{s})$ of contribution to São Francisco river. Since then, it presents a continuous decreasing pattern, reaching in $49 \%$ ( $\left.390 \mathrm{~m}^{3} / \mathrm{s}\right)$. Regardless of the causes of declining (natural or human-induced), measures must be taken to ensure sustainable water usage, since the systematic decreasing of potable water leads to extensive socio-economic stresses.
\end{abstract}

DOI: http://dx.doi.org/10.14295/ras.v32i1.28916

\section{INTRODUÇÃO}

O Rio São Francisco é o maior curso d'água exclusivamente brasileiro (CBHSF, 2015), nasce na Serra da Canastra, Minas Gerais, e ao longo de $2.700 \mathrm{~km}$ percorre sete unidades federativas para então desaguar no Oceano Atlântico, na divisa entre Sergipe e Alagoas. A bacia hidrográfica do Rio São Francisco (BHRSF) distribui-se por cerca de $638 \mathrm{~km}^{2}$, comporta cinco das principais usinas hidroelétricas do país e abriga 14,3 milhões de pessoas (CBHSF, 2016). Além das recentes obras de transposição do Rio São Francisco para o semiárido nordestino, cujo projeto pretende garantir a segurança hídrica de cerca de 12 milhões de pessoas, a manutenção da operação das hidroelétricas e o crescimento populacional da bacia, estimado em até 20,5 milhões de habitantes para 2035 , fomentam os estudos de disponibilidade e ge- renciamento dos recursos hídricos na BHRSF (CBHSF, 2015).

Nesse contexto, inclui-se o Sistema Aquífero Urucuia (SAU), que está situado na porção média da bacia hidrográfica do Rio São Francisco e seu fluxo de base contribui significativamente com a permanência de afluentes da margem esquerda do São Francisco e para manutenção das vazões no período de estiagem. 0 SAU é um aquífero poroso, composto por arenitos flúvio-eólicos neocretáceos do Grupo Urucuia; apresenta espessura máxima de 350 metros e distribui-se por 125.000 km² (CHANG; SILVA, 2015). As reservas reguladora e permanente, estimadas em $22,37 \mathrm{~km}^{3} /$ ano e $1.329 \mathrm{~km}^{3}$ (ANA, 2013), respectivamente, representam $41 \%$ da disponibilidade hídrica subterrânea da BHRSF (ANA, 2004; CBHSF, 2016). A contribuição média do fluxo de base do SAU perfaz cerca de $30 \%$ da vazão média do Rio São 
Francisco (ANA, 2013), sendo o principal aquífero na manutenção da vazão do Rio São Francisco (CBHSF, 2016).

A principal área de afloramento do SAU está compreendida no oeste do estado da Bahia, região onde, a partir da década de 1980, o crescimento agrícola suprimiu a vegetação nativa (Cerrado em sua maioria) e implantou extensas áreas de lavoura (BRANNSTROM et al., 2008; SPAGNOLO et al., 2012). Além das alterações no uso e ocupação do solo, a expansão agrícola exige intensa utilização dos recursos hídricos para irrigação de plantações e dessedentação animal.

A aquisição de dados fluviométricos e o monitoramento sistemático dos cursos d'água resultam em séries históricas relevantes no diagnóstico da disponibilidade hídrica subterrânea e superficial (MILLER et al., 2016). A separação dos escoamentos superficial e subterrâneo em hidrogramas consiste em um método simples e eficaz para quantificar a contribuição do escoamento de base do aquífero e a interação das águas subterrâneas e superficiais (ZHANG et al., 2017). De posse deste conhecimento, comumente são utilizados softwares de simulação hidrológica e de fluxo de águas subterrâneas (ENGELBRECHT; CHANG, 2015; GONÇALVES; CHANG, 2017) para uma compreensão mais aprofundada da dinâmica e evolução do balanço hídrico, tanto em caráter local quanto regional.

A elaboração de um plano adequado de gestão e manejo das águas subterrâneas do SAU é fundamental para que a explotação do aquífero não comprometa o escoamento de base para o Rio São Francisco. O uso indiscriminado da água e as captações clandestinas, no entanto, dificultam a quantificação do balanço hídrico do aquífero e o desenvolvimento de uma política efetiva de gestão dos recursos hídricos. Para um plano de gestão integrada eficiente, portanto, é primordial compreender a dinâmica de fluxo das águas subterrâneas e sua interação com as águas superficiais ao longo do tempo, para assim imprimir esforços na identificação das causas e impactos de suas variações.

A compreensão da variação temporal do escoamento subterrâneo em séries históricas longas permite fazer inferências a respeito de ciclos hidrológicos naturais, variações climáticas e efeitos da explotação de água subterrânea. Dessa maneira, o foco deste trabalho recai sobre o comportamento do escoamento subterrâneo ao longo do tempo (ciclos, ganhos, perdas e tendências), com o objetivo principal de analisar a variação temporal do fluxo de base do Sistema Aquífero Urucuia em todas as sub-bacias tributárias do Rio São Francisco e estimar a contribuição do aquífero para a manutenção da vazão do rio. Buscou-se, ainda, entender a variação da contribuição do aquífero dentro de cada sub-bacia, a relação entre as sub-bacias e possíveis mudanças no fluxo da água em seu percurso até o Rio São Francisco.

\section{2. ÁREA DE ESTUDO}

A área de estudo localiza-se majoritariamente no oeste do estado da Bahia e norte de Minas Gerais, entre as latitudes $10^{\circ} 00^{\prime}$ e $16^{\circ} 00^{\prime}$ Sul e longitudes $44^{\circ} 00^{\prime}$ e $46^{\circ} 30^{\prime}$ Oeste. Embora o Sistema Aquífero Urucuia ocorra em porções dos estados de Goiás, Tocantins, Maranhão e Piauí, estas são menos importantes em termos de área e contribuição (ANA, 2013) (Figura 1).

\section{MATERIAIS E MÉTODOS}

Para análise da contribuição hídrica do SAU para o Rio São Francisco, foram estudadas separadamente as sub-bacias hidrográficas referentes aos principais rios que seccionam o sistema aquífero - Preto, Grande, Corrente, Carinhanha e Pandeiros (Figura 1). Em cada sub-bacia foram selecionados os postos fluviométricos localizados no interior e próximo ao exutório do SAU, que representam as condições do sistema, e nos trechos entre o SAU e o Rio São Francisco, que são influenciados pelas unidades aquíferas (quando presentes) a jusante do SAU. A área de drenagem de cada estação fluviométrica foi delimitada por meio do software ArcGIS 10.0 (ESRI ${ }^{\mathrm{TM}}$ ), utilizando imagens SRTM (Shuttle Radar Topography Mission) com resolução espacial horizontal de 30 metros.

Os dados referentes às séries históricas fluviométricas foram obtidos no Hidroweb, banco de dados hidrológicos online da Agência Nacional de Águas (ANA). Previamente ao tratamento e análise dos dados, foram descartados as estações e intervalos carentes de dados. Ao todo foram analisadas neste trabalho 45 estações fluviométricas, responsáveis por monitorar desde longos períodos (a partir da década de 1930) até tempos recentes (após ano 2000), distribuídas em todo o SAU.

\subsection{Separação dos escoamentos superficial e subterrâneo}

A separação dos escoamentos superficial e subterrâneo consiste em prática corriqueira na avaliação da disponibilidade hídrica e recarga de aquíferos livres. 0 método de análise por filtros digitais recursivos (FDR), desenvolvido por Pettyjonh e Henning (1979), consiste no emprego de equações matemáticas para um intervalo de tempo predefinido, obtendo-se os pontos de menor vazão ao longo do hidrograma. A aplicação dos filtros digitais recursivos por meio de rotinas computacionais permite a análise sistemática do hidrograma, o que evita inconsistências inerentes ao método manual e acelera os cálculos (SLOTO; CROUSE, 1996).

Para este estudo foi desenvolvida uma rotina computacional em ambiente Visual Basic for Applications (VBA), utilizando o método de separação por mínimos locais. A rotina computacional analisa o intervalo de tempo proporcional ao tempo de recessão (TR) da bacia hidrográfica (Figura 2). A fundamentação teórica do método dos mínimos locais e o cálculo do período de recessão estão devidamente esclarecidos nos trabalhos de Sloto e Crouse (1996) e Gonçalves, Engelbrecht e Chang (2016). 
Figura 1 - Mapa regional de ocorrência do SAU e localização das principais sub-bacias

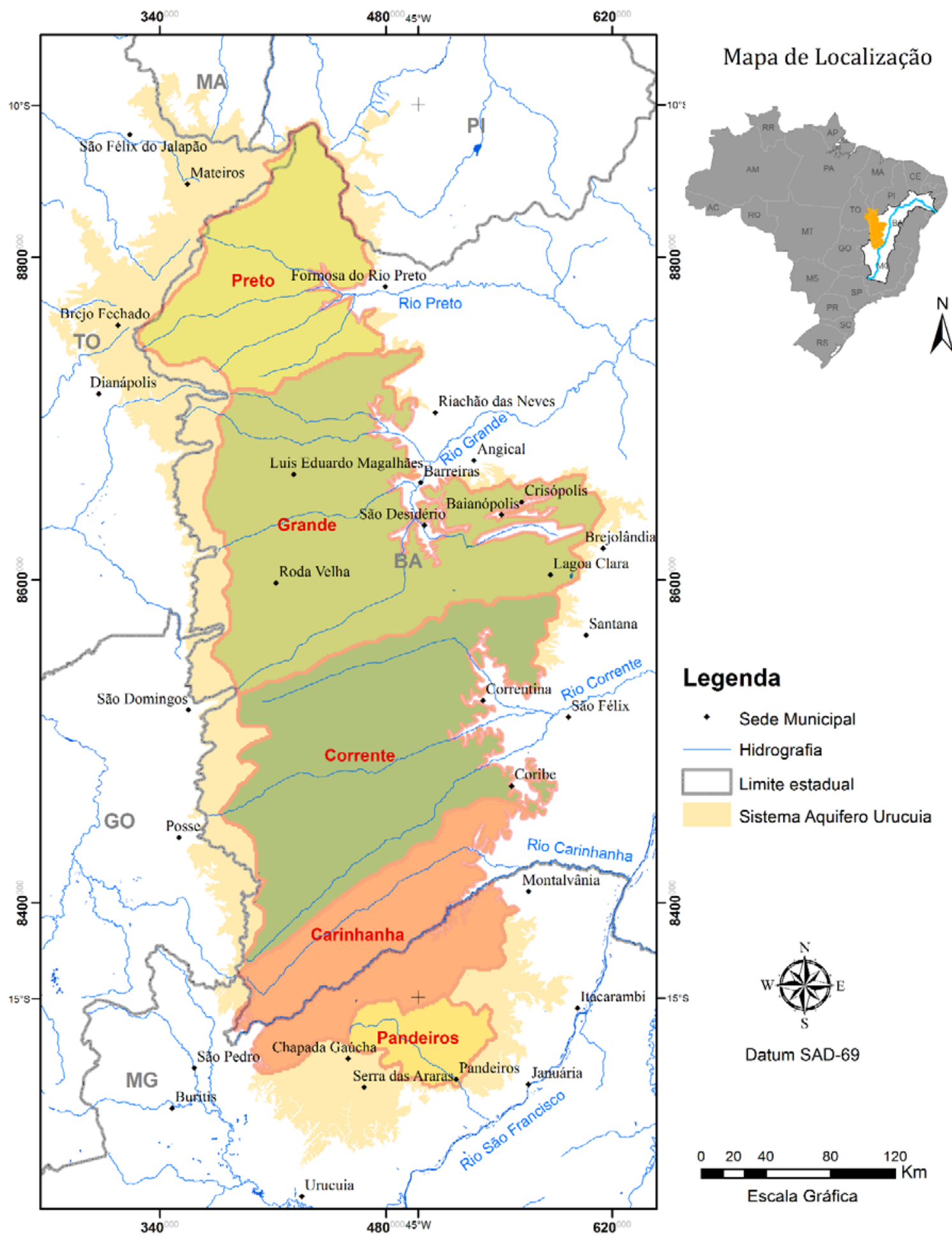


Figura 2 - (A) Hidrograma tipo em que: TC - tempo de concentração da bacia, TP - tempo de pico, TR - tempo de recessão (adaptado de TUCCI, 2009); (B) Exemplo de separação de hidrogramas por mínimos locais (adaptado de SLOTO e CROUSE,1996)

A)

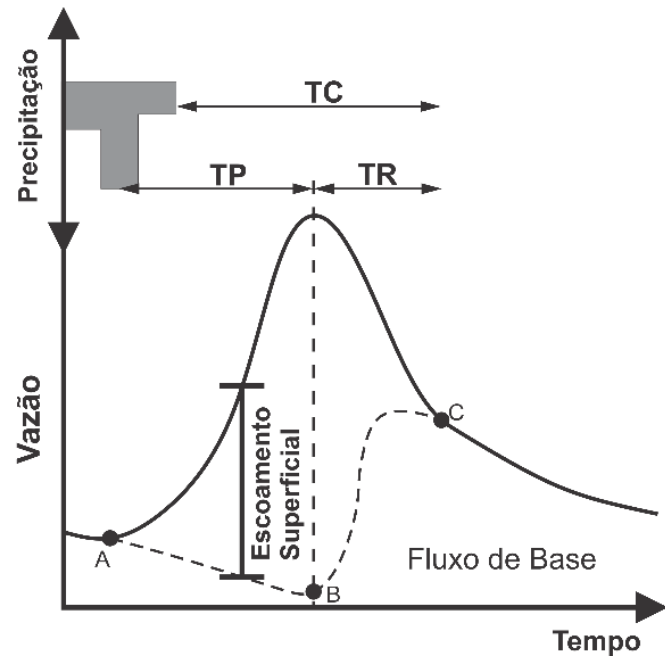

B)

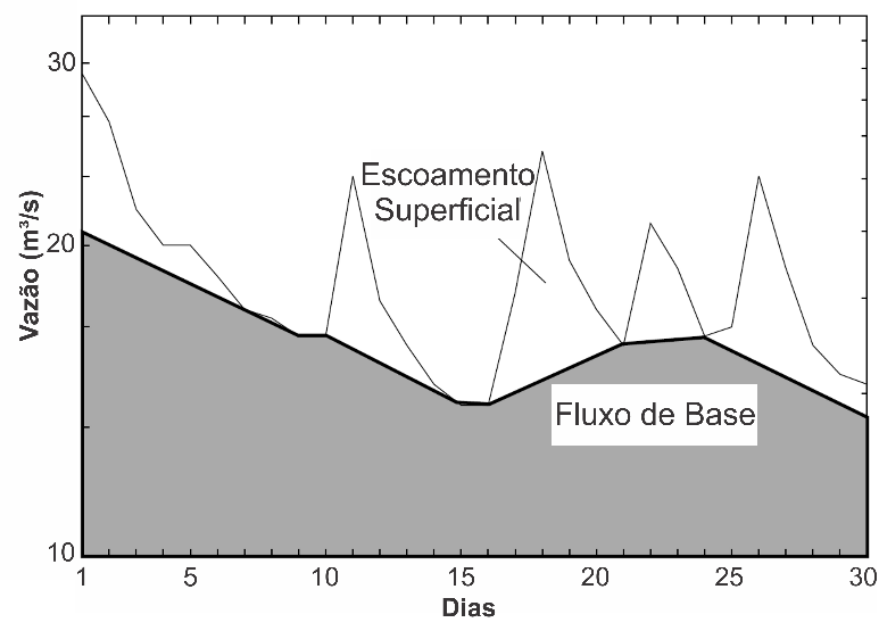

\subsection{Quantificação dos escoamentos}

Após a separação dos escoamentos superficial e subterrâneo, o volume diário dos escoamentos total, subterrâneo e superficial foi quantificado pelas equações 1, 2 e 3, respectivamente (ver MIRANDA, 2012). Os volumes diários dos escoamentos foram então divididos pela área de drenagem de cada bacia hidrográfica, convertendo-os para lâmina d'água, em mm, conforme a Equação 4. A normalização dos volumes de escoamento para lâmina d'água permite comparar a contribuição de bacias com diferentes áreas. Por fim, a análise da evolução da contribuição do fluxo de base do SAU considerou períodos anuais, cujos valores compreendem a somatória das lâminas diárias ao longo do ano considerado.

$$
\begin{gathered}
V(i)=\int_{t i}^{t i+1} Q(i) d t=\frac{\left(Q_{(i+1)}+Q_{(i)}\right)}{2} * \Delta t \\
V_{E S u b(i)}=\int_{t i}^{t i+1} Q_{E S u b(i)} d t=\frac{\left(Q_{E S u b(i+1)}+Q_{E S u b(i)}\right)}{2} * \Delta t \\
\mathrm{~V}_{\mathrm{ES}(\mathrm{i})}=\mathrm{V}_{(\mathrm{i})}-\mathrm{V}_{\mathrm{ESub}(\mathrm{i})} \\
H_{(\mathrm{i})}=\frac{V_{(i)}}{A_{\text {bacia }}} * 10^{-3}
\end{gathered}
$$

Em que: Vt(i) é o volume do escoamento total no dia i, em m³; Ves (i) é o volume do escoamento superficial no dia i, em m³; VESub(i) é o volume do escoamento subterrâneo no dia i, em m³; Q(i) é a vazão do dia i, obtida da base de dados da estação fluviométrica, em $\mathrm{m}^{3} \mathrm{~s}^{-1} ; \Delta$ t é o intervalo de tempo diário, igual a 86400 segundos; QESub(i) é a vazão correspondente ao escoamento subterrâneo no dia i, obtido a partir da separação do hidrograma, em $\mathrm{m}^{3} \mathrm{~s}^{-1}$; H (i) é a lâmina de água no dia i, em mm; V (i) é o volume do escoamento no dia i, em $\mathrm{m}^{3}$; e Abacia é a área da bacia, em $\mathrm{km}^{2}$.

\section{RESULTADOS E DISCUSSÃO}

\subsection{Evolução do fluxo de base na sub-bacia do Rio Preto}

A sub-bacia do Rio Preto localiza-se no extremo norte da área, e para sua análise são utilizadas cinco estações fluviométricas distribuídas ao longo do rio principal, sendo uma localizada no afluente Rio Sapão antes de encontrar o Rio Preto (Figura 3). 
Figura 3 - Estações fluviométricas da sub-bacia do Rio Preto e respectivas séries históricas de fluxo de base

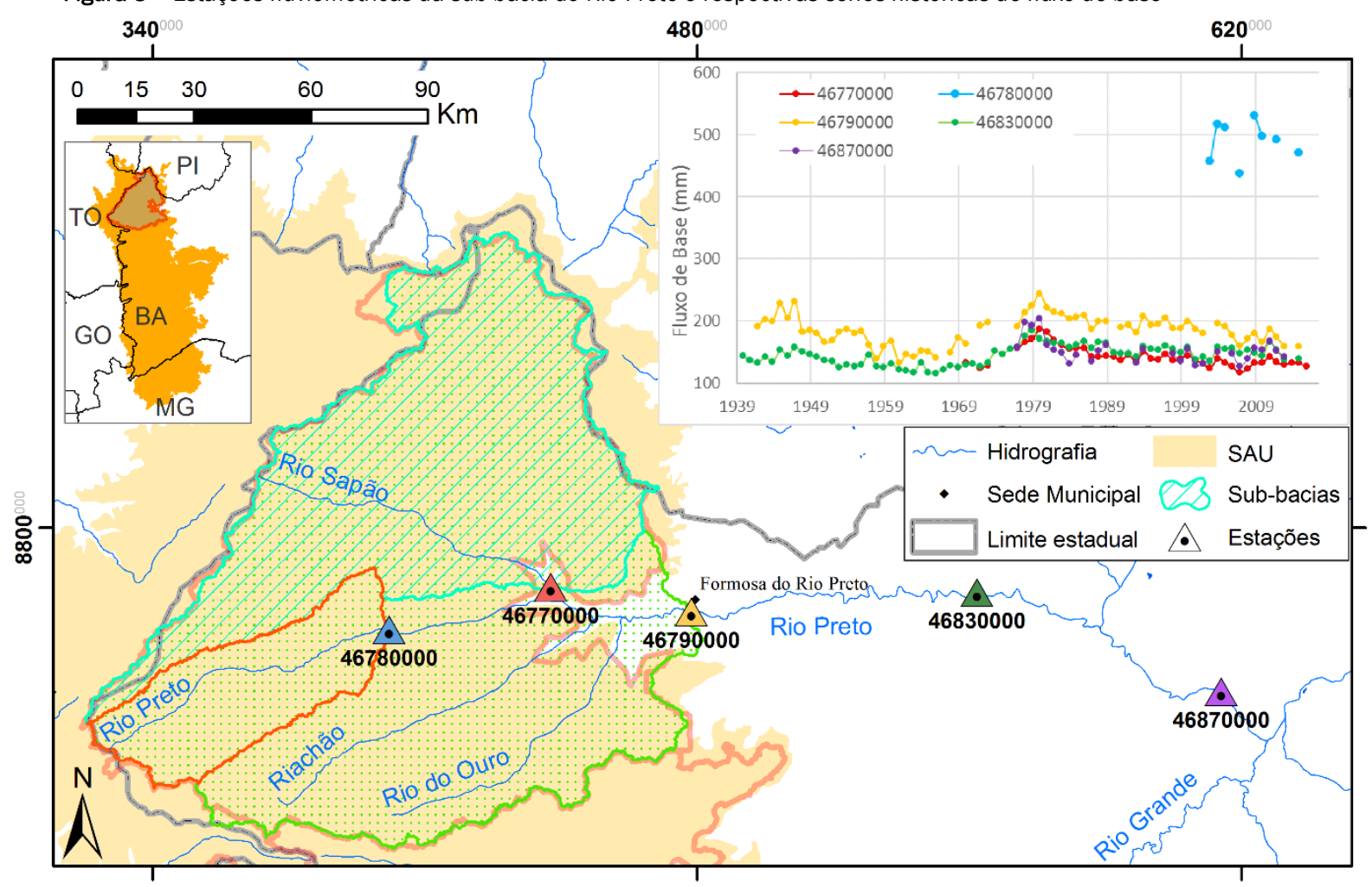

A porção oeste da bacia do Rio Preto (estação 46780000), onde ocorre maior espessura do SAU e maior pluviosidade (ANA, 2013), apresenta o maior fluxo de base da bacia e contribui, em média, com $480 \mathrm{~mm} / \mathrm{a}\left(29 \mathrm{~m}^{3} / \mathrm{s}\right)$ para esse fluxo. Já a porção norte da bacia (estação 46770000), contribui em média com 140 mm/a (31 m³/s). Na saída do Rio Preto da área do SAU (estação 46790000), verifica-se uma contribuição para o fluxo de base de, em média, $180 \mathrm{~mm} / \mathrm{a}(83 \mathrm{~m} 3 / \mathrm{s})$; esta estação apresenta comportamento típico do fluxo de base do SAU na bacia do Rio Preto. Assim, a porção oeste e sul da bacia são as que mais contribuem para o fluxo de base do Rio Preto. Fora dos domínios do SAU, as estações 46830000 e 46870000 indicam claramente que há menos descarga de aquíferos a jusante do Sistema Aquífero Urucuia.

As séries históricas mais longas mostram claramente dois ciclos, com picos no início dos anos 1940 e depois em 1980. O primeiro grande ciclo mostrou uma queda significativa até os anos 1960 (cerca de 20 anos de queda), porém uma forte recuperação nos anos seguintes. Da década de 1980 até o presente não há indícios de uma nova subida, tornando esta queda muito mais longa do que a anterior.

\subsection{Evolução do fluxo de base na sub-bacia do Rio Grande}

A sub-bacia do Rio Grande possui a melhor rede hidrometeorológica da região, e para uma análise mais completa desse afluente tão importante para o Rio São Francisco, foram utilizadas 19 estações fluviométricas que abrangem diferentes períodos de tempo (Figura 4). Avaliando o rio principal, a parte sul (estação 46550000) apresenta uma queda pronunciada do fluxo de base a partir dos anos 1980, saindo do patamar de $150 \mathrm{~mm} / \mathrm{a}$ (110 $\mathrm{m}^{3} / \mathrm{s}$ ) desde a década de 1930, para abaixo de $100 \mathrm{~mm} / \mathrm{a}$ (70 $\mathrm{m}^{3} / \mathrm{s}$ ). Já a porção norte da bacia (estação 46590000) não sofreu tanto nesse segundo ciclo, como evidenciado pelo alto valor do fluxo de base de $190 \mathrm{~mm} / \mathrm{a}\left(45 \mathrm{~m}^{3} / \mathrm{s}\right)$.

Ao investigar mais profundamente a porção norte da bacia (Figura 5), verifica-se que os rios de Ondas e Cabeceira das Pedras (estações 46520000, 46530000 e 465430000) recebem grande contribuição do SAU, entre 250 mm/a e 340 mm/a em média, e o Rio Branco (estação 46784000) no extremo norte com muito mais fluxo de base do que o Rio Janeiro (estações 46570000 e 46585000). A confluência destes dois últimos forma o fluxo da estação 4659000 (190 mm/a, 45 m³/s), que por sua vez se soma com a contribuição do Rio de Ondas (estação 46543000; 250 mm/a, 43 m³/s) e os demais rios da porção sul. 
Figura 4 - Estações fluviométricas da sub-bacia do Rio Grande e respectivas séries históricas de fluxo de base

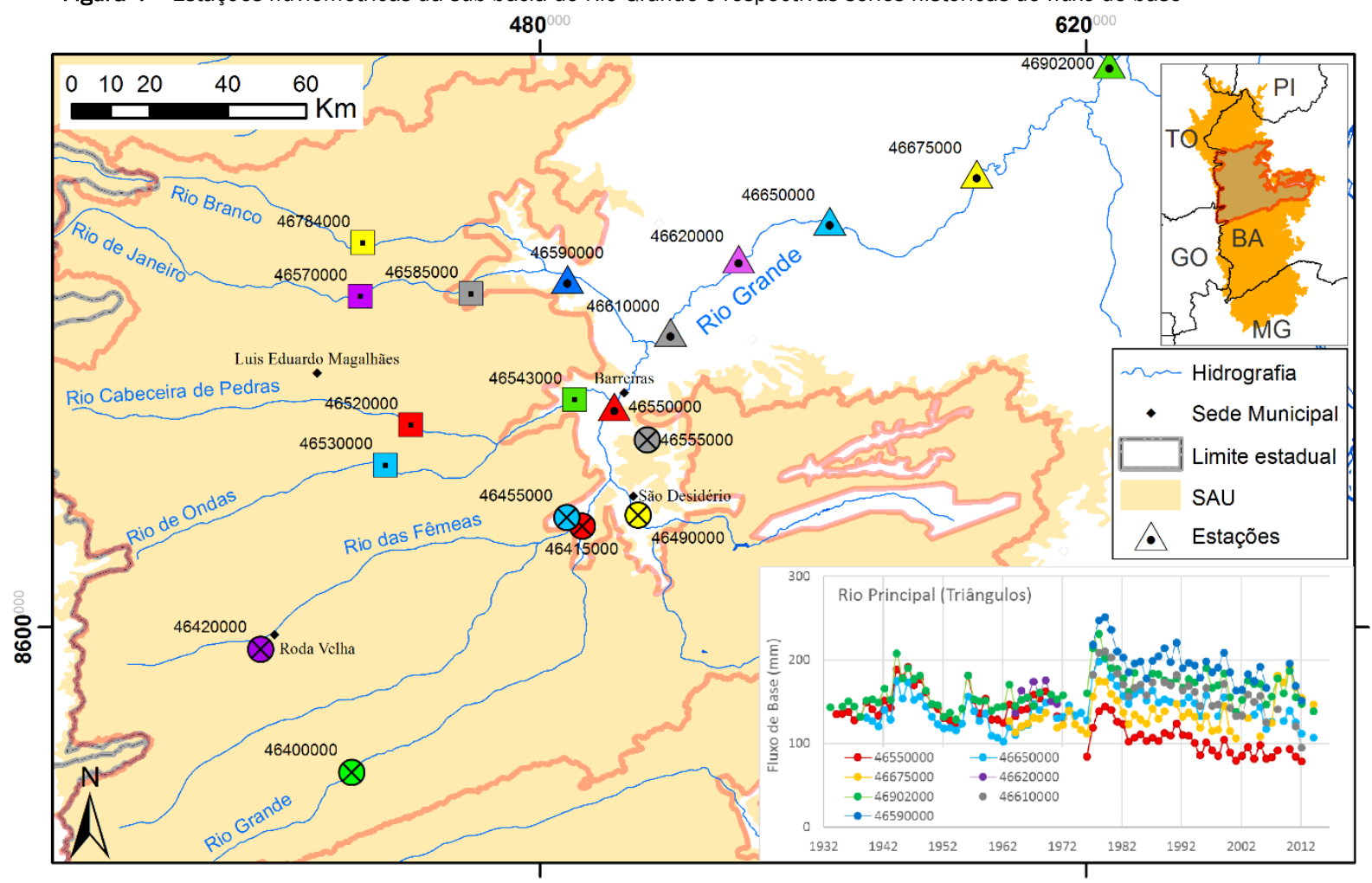

Avaliando a porção sul da bacia (Figura 5), os rios que drenam a parte leste (estações 46490000 e 46555000 ) têm escassa contribuição do SAU, perfazendo menos de $40 \mathrm{~mm} / \mathrm{a}\left(5 \mathrm{~m}^{3} / \mathrm{s}\right)$, indicativo de que há um volume significativo infiltrando no embasamento metacalcário presente nesta área (GONÇALVES; ENGELBRECHT; CHANG, 2016). A oeste (estações 46455000 e
46415000) verifica-se forte contribuição do SAU, em torno de $200 \mathrm{~mm} / \mathrm{a}\left(70 \mathrm{~m}^{3} / \mathrm{s}\right)$, e sobretudo no extremo oeste (estações 46420000 e 46400000 ), com valores superiores a 300 mm/a. A confluência de todos os afluentes do Rio Grande no SAU é responsável pelo fluxo de base de $150 \mathrm{~mm} /$ a verificado na estação $46610000\left(160 \mathrm{~m}^{3} / \mathrm{s}\right)$.

Figura 5 - Séries históricas de fluxo de base das estações fluviométricas da sub-bacia do Rio
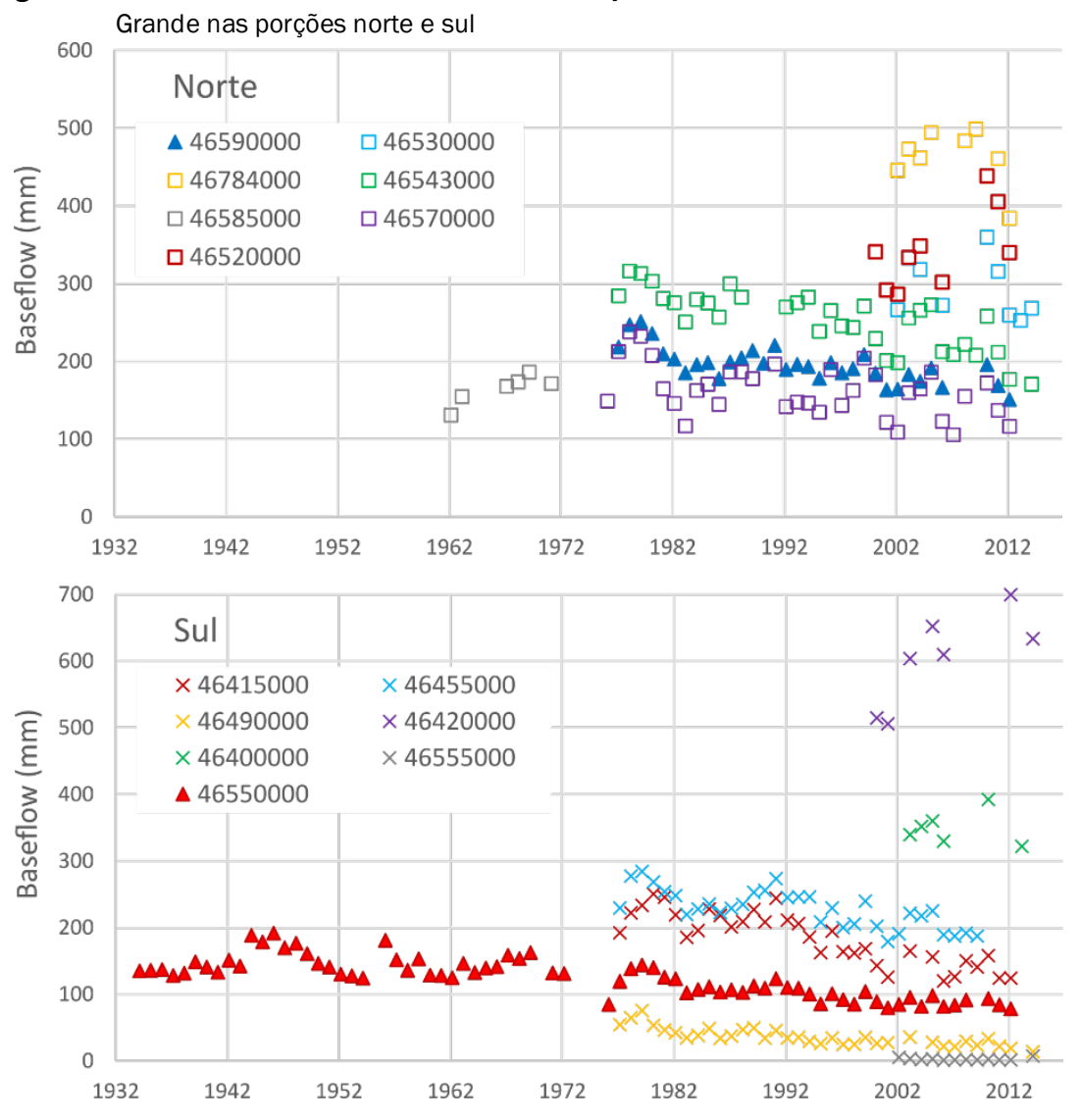
Fora dos domínios do SAU, a queda do fluxo de base entre as estações 46610000, 46650000 e 46675000 evidencia diminuição na descarga de aquíferos nesse trajeto. No entanto, o aumento da contribuição do fluxo de base entre as estações 46675000 e 46902000 , de $135 \mathrm{~mm} / \mathrm{a}\left(170 \mathrm{~m}^{3} / \mathrm{s}\right)$ para 163 $\mathrm{mm} / \mathrm{a}\left(240 \mathrm{~m}^{3} / \mathrm{s}\right)$, indica descarga de águas subterrâneas, possivelmente relacionada ao aquífero cárstico presente nessa região (GONÇALVES; CHANG, 2017). É importante salientar que essas águas podem ser provenientes do compartimento sudeste do SAU na bacia do Rio Grande (GONÇALVES; ENGELBRECHT; CHANG, 2016).

\subsection{Evolução do fluxo de base na sub-bacia do Rio Corrente}

Para a análise da evolução do fluxo de base na sub-bacia do Rio Corrente foram consideradas 12 estações fluviométricas ao longo dos quatro principais afluentes: rios Guará, Correntina, Arrojado e Formoso (Figura 6). As séries históricas nesta bacia abrangem períodos distintos, sendo cinco estações monitoradas a partir dos anos 2000 e apenas sete estações com monitoramento mais longo, seis com início no final dos anos 1970 e apenas a estação 45840000, localizada na saída do Rio Formoso da área do SAU, com monitoramento desde os anos 1950.

Figura 6 - Estações fluviométricas da sub-bacia do Rio Corrente e respectivas séries históricas de fluxo de base

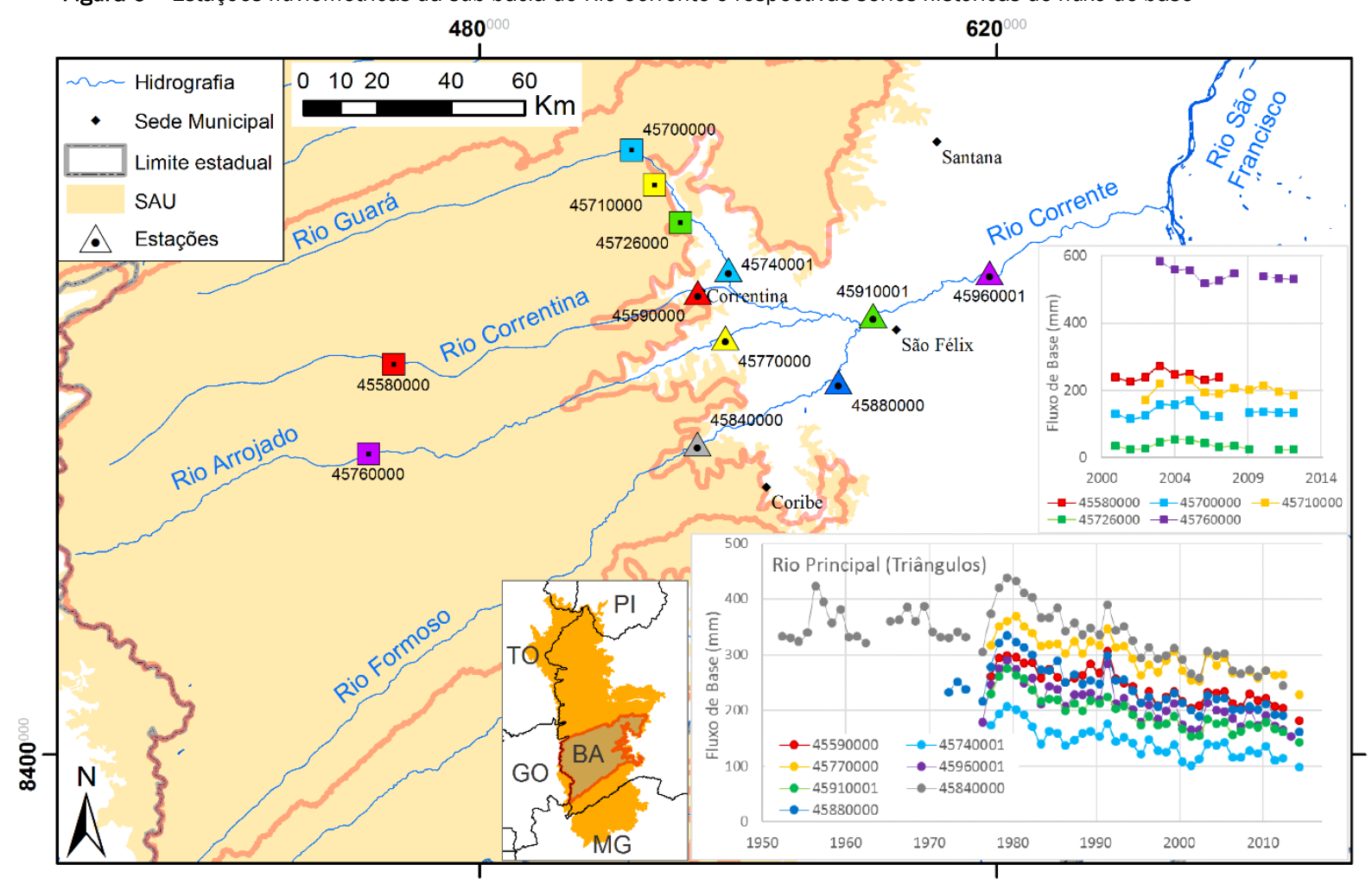

Dentre os afluentes do Rio Corrente, os rios Formoso (estação 45840000) e Arrojado (estação 45770000) são os que apresentam maior contribuição do fluxo de base, com médias de 332 $\mathrm{mm} / \mathrm{a}\left(74 \mathrm{~m}^{3} / \mathrm{s}\right)$ e $295 \mathrm{~mm} / \mathrm{a}\left(52 \mathrm{~m}^{3} / \mathrm{s}\right)$, respectivamente. No Rio Arrojado, as diferenças entre as estações 45760000 (mais a oeste) e 45770000 (a leste, na saída do rio da área do SAU) indicam que há maior contribuição do SAU em direção à borda oeste. É importante pontuar que valores muito altos, como 600 $\mathrm{mm} / \mathrm{a}$, podem estar sofrendo influência de represamentos próximos.

Na porção norte da sub-bacia, com menor contribuição para o fluxo de base, o Rio Correntina (estações 45580000 e $45590000)$ contribui com pouco mais de $240 \mathrm{~mm} / \mathrm{a}\left(30 \mathrm{~m}^{3} / \mathrm{s}\right)$, enquanto que o Rio Guará e seus afluentes contribuem com menos de 200 mm/a de lâmina de fluxo de base (estações 45700000 e 45710000 ). Os baixos valores de fluxo de base das estações distantes dos domínios do SAU (estações 45880000, 45910001 e 45960001) em relação aos principais afluentes na saída da área do SAU indicam que não há contribuição importante de outros aquíferos no trajeto até o Rio São Francisco. A contribuição efetiva do SAU para a sub-bacia do Rio Corrente pode ser computada considerando-se as estações que estão nas saídas dos principais afluentes da área do SAU: 45840000 , 45770000, 45590000 e 45740001 . Assim, tem-se uma contribuição média para o fluxo de base de 247 mm/a (190 m³/s).

Assim como nas sub-bacias acima, evidencia-se um ciclo a partir de 1980, com queda proeminente e contínua desde então. Apenas o Rio Formoso possui dados mais antigos, que indicam dois ciclos menores em concordância com as séries do Rio Grande, porém em patamares bem mais altos. Portanto, baixas vazões como as recentes não estão documentadas em nenhum momento no passado desta sub-bacia.

\subsection{Evolução do fluxo de base nas sub-bacias do sul (rios Cari- nhanha e Pandeiros)}

Os principais rios que escoam a porção sul do SAU são os rios Carinhanha - com contribuições dos rios Itaguari e Coxá - e Pandeiros (Figura 7). 
Figura 7 - Estações fluviométricas das sub-bacias do sul e respectivas séries históricas de fluxo de base

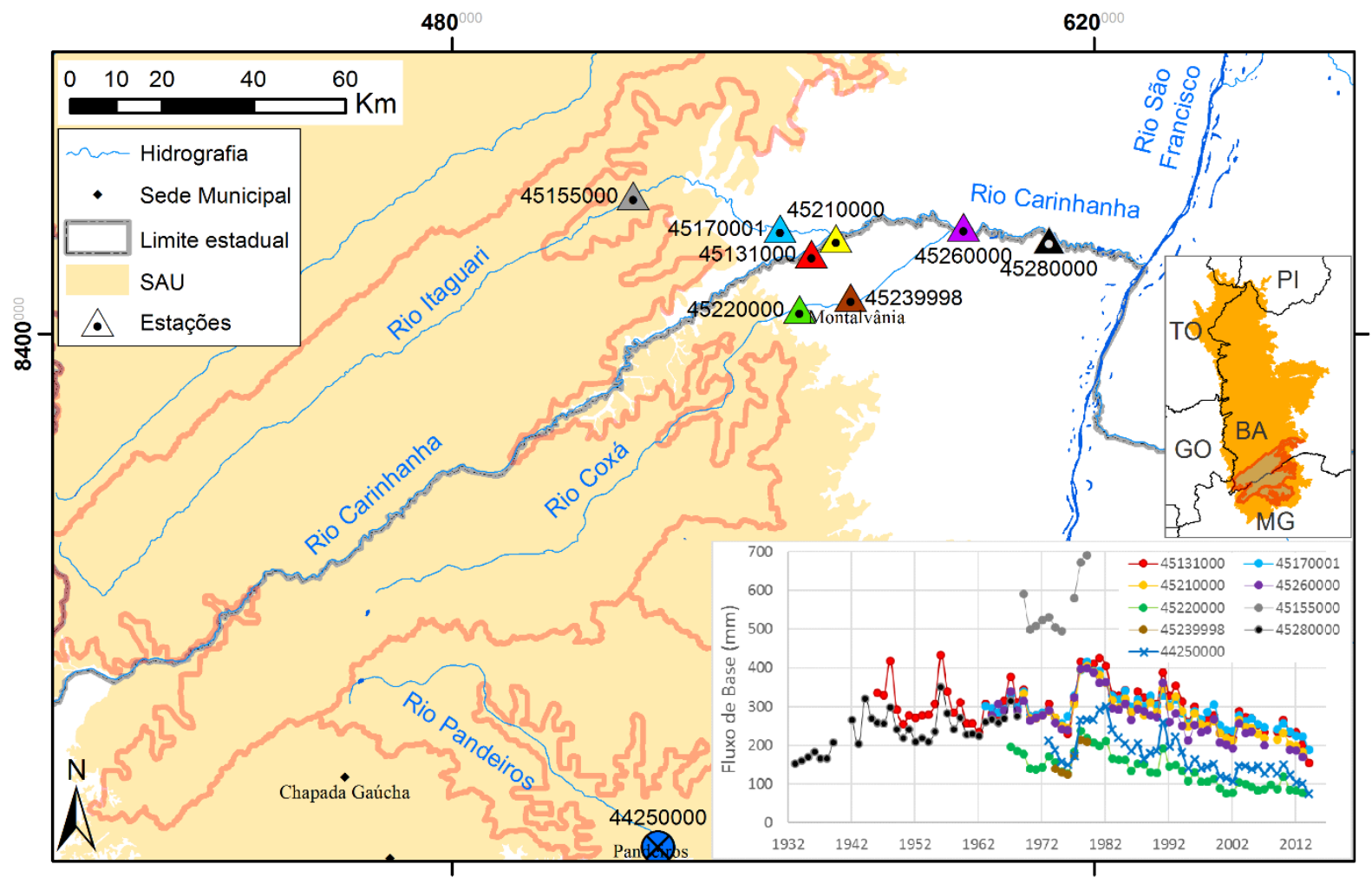

Na sub-bacia do Rio Carinhanha, os rios Itaguari (45170001) e Carinhanha (estação 45131000) contribuem com fluxos de base semelhantes (aproximadamente $300 \mathrm{~mm} / \mathrm{a}, 55 \mathrm{~m}^{3} / \mathrm{s}$ cada), perfazendo $110 \mathrm{~m}^{3} / \mathrm{s}$ ao se encontrarem (estação 45210000), enquanto o Rio Coxá (estação 45220000), mais a sul, contribui com apenas $140 \mathrm{~mm} / \mathrm{a}\left(10 \mathrm{~m}^{3} / \mathrm{s}\right)$. Como as estações analisadas estão relativamente distantes das porções mais espessas do $\mathrm{SAU}$, as lâminas correspondentes aos fluxos de base incluem uma área expressiva fora do SAU, dificultando assim o cálculo com exatidão da variação da parcela de contribuição do Sistema Aquífero Urucuia. No entanto, para as estações mais distantes (estações 45260000 e 45280000 ), verifica-se contribuição de $235 \mathrm{~mm} / \mathrm{a}$ do fluxo de base; são $120 \mathrm{~m}^{3} / \mathrm{s}$ que refletem a exata soma dos três principais afluentes, atestando a contribuição exclusiva do SAU para o fluxo de base até o Rio São Francisco.

No extremo sul do SAU, o Rio Pandeiros possui apenas uma estação fluviométrica (estação 44250000), de forma que a análise é simples e direta, e não permite analisar a variação do fluxo de base ao longo do rio. A contribuição média do SAU para o Rio Pandeiros é de cerca de $173 \mathrm{~mm} /$ ano $\left(18 \mathrm{~m}^{3} / \mathrm{s}\right)$, um pouco mais que para o Rio Coxá, a norte. A porção sul do SAU também apresenta queda do fluxo de base a partir da década de 1980; no entanto, dados mais antigos mostram variabilidade maior em relação às bacias do norte. É importante pontuar diferenças como taxas de precipitação e uma espessura muito menor do SAU na região sul, tornando os rios mais suscetíveis às variações sazonais de chuvas.

\subsection{Contribuição do SAU para o Rio São Francisco}

É importante ressaltar que a utilização de médias em diferentes períodos históricos deve ser cuidadosa, pois pode acarretar em conclusões imprecisas e cálculos de reservas errôneos, já que, como visto nas análises históricas acima, o comportamento ao longo do tempo pode ser extremamente variável. As médias históricas das estações utilizadas encontram-se na Tabela 1.

A média histórica do fluxo de base do SAU para o Rio São Francisco soma aproximadamente $200 \mathrm{~mm} / \mathrm{ano}\left(570 \mathrm{~m}^{3} / \mathrm{s}\right)$, e representa, em média, entre $89 \%$ e $95 \%$ do escoamento total dos rios. Analisando a evolução no último ciclo pós-1980 (Figura 8), o fluxo de base de todo o SAU para o Rio São Francisco foi de 280 $\mathrm{mm} /$ ano $\left(792 \mathrm{~m}^{3} / \mathrm{s}\right)$ no pico em 1980 , enquanto os dados anuais mais recentes se encontram em aproximadamente 134 $\mathrm{mm} / \mathrm{ano}\left(402 \mathrm{~m}^{3} / \mathrm{s}\right)$, revelando queda vertiginosa de 49\% (390 $\mathrm{m}^{3} / \mathrm{s}$ ). Nota-se ainda que todas as sub-bacias apresentam quedas significativas neste período. No entanto, as séries mais antigas de algumas sub-bacias também apresentam quedas proeminentes do fluxo de base em ciclos mais antigos. Por exemplo, observam-se quedas importantes no fluxo de base para o Rio Preto entre os anos 1940 e 1960, e com variabilidade ainda mais intensa. No Rio Grande vê-se claramente ciclos menores nas séries mais antigas, assim como no Rio Corrente. Já o sul traz comportamentos distintos, com uma grande variabilidade nos valores de fluxo de base mais antigos.

Ou seja, tanto as variações recentes quanto as mais antigas (muitas vezes não incorporadas aos cálculos de reserva e disponibilidade) mostram variação muito elevada em relação a qualquer média, independente do período a ser utilizado para o cálculo. 
Figura 8 - Séries históricas de fluxo de base anual das sub-bacias e do SAU no ciclo pós-1980

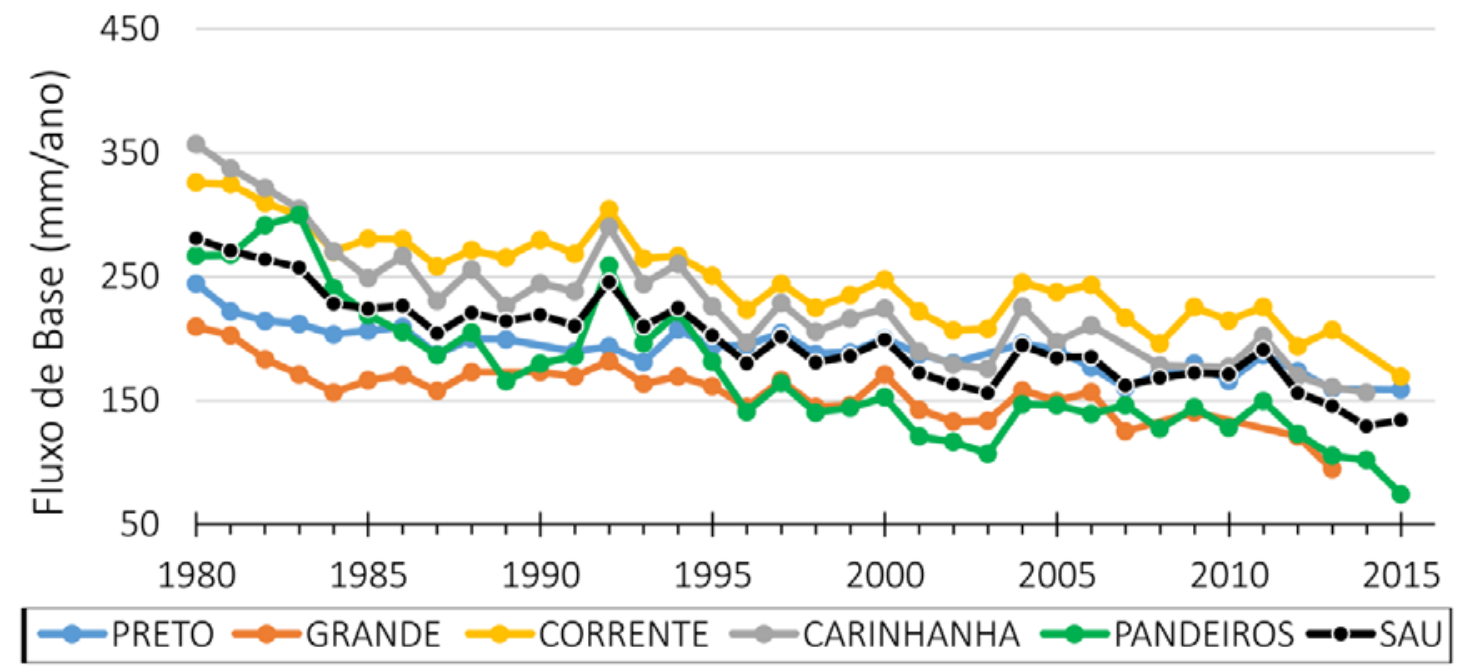

Tabela 1 - Médias históricas do fluxo de base das estações fluviométricas

\begin{tabular}{|c|c|c|c|c|c|c|c|c|c|}
\hline \multirow{2}{*}{\multicolumn{2}{|c|}{$\begin{array}{c}\text { Estação Área }\left(\mathrm{km}^{2}\right) \\
\text { Rio Preto }\end{array}$}} & \multicolumn{2}{|c|}{$\begin{array}{c}\text { Fluxo de Base Mé- } \\
\text { dio }\end{array}$} & \multirow[t]{2}{*}{$\mathrm{BFI}{ }^{*}$} & Estação & Área $\left(\mathrm{km}^{2}\right)$ & \multicolumn{2}{|c|}{$\begin{array}{c}\text { Fluxo de Base Mé- } \\
\text { dio }\end{array}$} & \multirow[t]{2}{*}{$\mathrm{BFI}$ * } \\
\hline & & $\mathrm{m}^{3} / \mathrm{s}$ & $\mathrm{mm} / \mathrm{ano}$ & & \multicolumn{2}{|c|}{ Rio Corrente } & $\mathrm{m}^{3} / \mathrm{s}$ & $\mathrm{mm} / \mathrm{ano}$ & \\
\hline 46780000 & 1900 & 29,0 & 482,1 & 0,931 & 45580000 & 2095 & 15,8 & 237,8 & 0,938 \\
\hline 46770000 & 6930 & 31,2 & 141,8 & 0,938 & 45590000 & 3831 & 29,2 & 240,5 & 0,953 \\
\hline 46790000 & 14300 & 83,3 & 183,8 & 0,925 & 45700000 & 2122 & 9,0 & 134,1 & 0,939 \\
\hline 46830000 & 17900 & 82,1 & 144,7 & 0,928 & 45710000 & 2534 & 15,6 & 194,1 & 0,949 \\
\hline 46870000 & 22000 & 93,3 & 133,7 & 0,917 & 45726000 & 1296 & 1,3 & 32,8 & 0,895 \\
\hline \multicolumn{2}{|c|}{ Rio Grande } & & & & 45740001 & 7950 & 35.5 & 140,9 & 0,931 \\
\hline 46400000 & 938 & 10,1 & 339,4 & 0,942 & 45760000 & 1588 & 25,0 & 496,5 & 0,970 \\
\hline 46415000 & 4944 & 28,1 & 179,3 & 0,939 & 45770000 & 5594 & 52,3 & 294,9 & 0,943 \\
\hline 46420000 & 505 & 9,7 & 603,7 & 0,957 & 45840000 & 6981 & 73,6 & 332,3 & 0,950 \\
\hline 46455000 & 6329 & 45,5 & 226,8 & 0,944 & 45880000 & 9550 & 72,0 & 237,8 & 0,939 \\
\hline 46490000 & 4433 & 4,9 & 35,0 & 0,913 & 45910001 & 29600 & 182,4 & 194,4 & 0,930 \\
\hline 46520000 & 1492 & 16,0 & 338,5 & 0,939 & 45960001 & 31000 & 184,7 & 187,9 & 0,926 \\
\hline 46530000 & 1900 & 17,1 & 283,7 & 0,911 & \multicolumn{2}{|c|}{ Rio Carinhanha } & & & \\
\hline 46543000 & 5404 & 42,9 & 250,6 & 0,928 & 45131000 & 6020 & 56,6 & 296,4 & 0,909 \\
\hline 46550000 & 24427 & 91,7 & 118,4 & 0,924 & 45155000 & 3220 & 56,6 & 554,6 & 0,937 \\
\hline 46555000 & 2410 & 0,3 & 3,3 & 0,806 & 45170001 & 5850 & 54,1 & 291,9 & 0,937 \\
\hline 46570000 & 2710 & 11,5 & 134,0 & 0,887 & 45210000 & 12600 & 110,3 & 276,0 & 0,924 \\
\hline 46585000 & 3530 & 18,5 & 165,4 & 0,918 & 45220000 & 2380 & 10,3 & 136,1 & 0,920 \\
\hline 46590000 & 7479 & 45,2 & 190,6 & 0,933 & 45239998 & 2560 & 13,9 & 171,0 & 0,910 \\
\hline 46610000 & 33100 & 160,7 & 153,1 & 0,924 & 45260000 & 16300 & 121,6 & 235,2 & 0,917 \\
\hline 46620000 & 34000 & 150,4 & 139,5 & 0,922 & 45280000 & 16900 & 126,4 & 235,8 & 0,919 \\
\hline 46650000 & 36000 & 158,8 & 139,1 & 0,922 & \multicolumn{2}{|c|}{ Rio Pandeiros } & & & \\
\hline 46675000 & 39600 & 169,7 & 135,1 & 0,922 & 44250000 & 3230 & 17,7 & 173,1 & 0,899 \\
\hline 46784000 & 685 & 9,7 & 444,9 & 0,945 & & & & & \\
\hline 46902000 & 46400 & 239,8 & 163,0 & 0,933 & & & & & \\
\hline
\end{tabular}

* Em que, BFI corresponde ao baseflow index, cujo valor está limitado entre 0 e 1 (ou 0 a 100\% se multiplicado por 100) e representa a contribuição do fluxo de base na manutenção da vazão total do rio. Ou seja, o cálculo do BFI consiste na divisão do fluxo de base calculado (escoamento subterrâneo) pela vazão total do rio. 0 restante é atribuído ao escoamento superficial. 
Apesar do uso recorrente de médias para simplificar e facilitar cálculos e comparações na gestão dos recursos hídricos, para uma adequada compreensão do atual estado da relação do Sistema Aquífero Urucuia com o Rio São Francisco é imperativa a análise entre diferentes épocas e diferentes porções do aquífero para se entender o contexto dessa interação e subsidiar planejamentos futuros de gestão de águas com base em tendências e variações, e não somente em médias.

\section{CONCLUSÕES}

A análise de séries históricas em todas as sub-bacias permitiu a inferência de ciclos distintos presentes no último século, sendo o último grande pico em 1980. Ao longo do SAU há diferenças de duração e amplitude nos ciclos pré-1980, com grandes mudanças nos patamares do fluxo de base. Essa é uma indicação clara de que as vazões podem mudar amplamente ao longo do tempo, e que as médias podem variar drasticamente dependendo do período analisado e do local da estação escolhida. Em geral, o SAU tem maior contribuição nas porções oeste e central dos rios que o seccionam, onde são encontradas maiores espessuras do sistema aquífero. Todos os rios estudados apresentam o mesmo padrão de queda contínua no ciclo pós-1980, com uma pequena recuperação no início da década de 1990 . Esta queda, que compreende uma diminuição de $49 \%$ (cerca de $390 \mathrm{~m}^{3} / \mathrm{s}$ ) da contribuição do SAU para o Rio São Francisco, deve ser considerada em todos os seus aspectos na gestão de recursos hídricos e energéticos da bacia.

O comportamento desses ciclos pode estar sofrendo influência direta, não somente do regime natural de chuvas, mas também de efeitos antrópicos, como explotação de águas subterrâneas, captação de águas superficiais, represamento, irrigação e compactação do solo nas áreas de recarga. Desse modo, o ciclo mais recente tende a ter duração e variabilidade diferentes dos ciclos mais antigos, demandando assim investigações acerca do uso da água nos períodos mais recentes.

\section{REFERÊNCIAS}

ANA - AGÊNCIA NACIONAL DE ÁGUAS. Projeto de gerenciamento integrado das atividades desenvolvidas em terra na bacia do São Francisco. Subprojeto 4.5C - Plano Decenal de Recursos Hídricos da Bacia Hidrográfica do Rio São Francisco - PBHSF (2004-2013). Nota técnica. Disponibilidade hídrica quantitativa e usos consuntivos na bacia hidrográfica do rio São Francisco. Brasilia, 71 p. 2004.

ANA - AGÊNCIA NACIONAL DE ÁGUAS. Estudos Hidrogeológicos na Bacia Hidrográfica do São Francisco - Sistema Aquífero Urucuia/Areado e Sistema Aquífero Bambuí. 2013. Disponível em: <http://cbhsaofrancisco.org.br/?wpfb_dl=1825>. Acesso em: 4 ago. 2017.

BRANNSTROM, C. et al. Land change in the Brazilian Savanna (Cerrado), 1986-2002: Comparative analysis and implications for land-use policy. Land Use Policy, v. 25, n. 4, p. 579-595, 2008.
CHANG, H. K.; SILVA, F. DE P. E. Contribuição ao arcabouço geológico do Sistema Aquífero Urucuia. Geociências, v. 34, n. 4, p. 872-882, 2015.

CBHSF - COMITÊ DA BACIA HIDROGRÁFICA DO RIO SÃO FRANCISCO. Diagnóstico consolidado da Bacia Hidrográfica do Rio São Francisco. Relatório Parcial, volume 1. 489p. 2015.

CBHSF - COMITÊ DA BACIA HIDROGRÁFICA DO RIO SÃO FRANCISCO. Plano de Recursos Hídricos da Bacia Hidrográfica do Rio São Francisco 2016 - 2025. Relatório Final, volume 1 e 2. 520p. 2016.

ENGELBRECHT, B. Z.; CHANG, H. K. Simulação numérica do fluxo de águas do sistema aquífero urucuia na bacia hidrogeológica do Rio Corrente (BA). Águas Subterrâneas, v. 29, n. 2, p. 244, 30 out. 2015.

GONÇALVES, R. D.; CHANG, H. K. Modelo Hidrogeológico do Sistema Aquífero Urucuia na Bacia do Rio Grande (BA). Geociências, v. 36, n. 2, p. 205-220, 2017.

GONÇALVES, R. D.; ENGELBRECHT, B. Z.; CHANG, H. K. Análise hidrológica de séries históricas da Bacia do Rio Grande (BA): contribuição do Sistema Aquífero Urucuia. Águas Subterrâneas, v. 30, n. 2, p. 190, 26 jun. 2016.

MILLER, M. P. et al. The importance of base flow in sustaining surface water flow in the Upper Colorado River Basin. Water Resources Research, v. 52, n. 5, p. 3547-3562, maio 2016.

MIRANDA, A. C. R. Métodos de separação dos escoamentos superficial direto e subterrâneo: estudo de caso para a Bacia do Rio das Velhas. 2012. 83f. Dissertação (Mestrado em Engenharia Agrícola). Universidade Federal de Viçosa, Viçosa, 2012.

PETTYJOHN, W. A.; HENNING, R. Preliminary estimate of groundwater recharge rates, related streamflow and water quality in Ohio. Ohio State University. Water Resources Center Project Completion, Report N 552. Ohio, 323 p., 1979.

SLOTO, R. A.; CROUSE, M. Y. Hysep: a computer program for streamflow hydrograph separation and analysis. U.S. Geological Survey Water-Resources Investigations Report 96-4040, Lemoyne, Pennsylvania, 46 p., 1996.

SPAGNOLO, T. F. O. et al. Dinâmica da expansão agrícola do município de São Desidério (BA) entre os anos de 1984 a 2008, importante produtor nacional de soja, algodão e milho. Geo UERJ, v. 23, n. 2, p. 603-618, 2012.

TUCCI, C. E. M. Hidrologia: ciência e aplicação. 4. ed. Editora da UFRGS/ABRH Porto Alegre, 943 p., 2009.

ZHANG, J. et al. Evaluating relative merits of four baseflow separation methods in Eastern Australia. Journal of Hydrology, v. 549, p. 252-263, 2017. 